\section{Doppler ultrasound-guided endoscopic needle-knife treatment of an anastomotic stricture following subtotal colectomy}

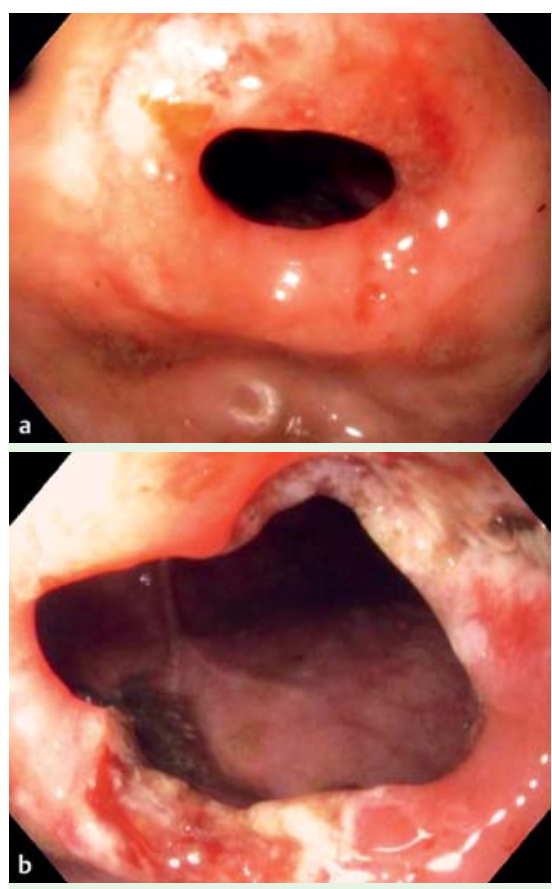

Fig. 1 lleorectal anastomotic stricture: a before and $\mathbf{b}$ after Doppler ultrasound-guided needle-knife therapy.

A 28-year-old woman presented to our clinic with a 2-month history of dyschezia after subtotal colectomy and ileorectal anastomosis (IRA). Sigmoidoscopy showed a 5-mm long, nonulcerated IRA stricture (๑ Fig. 1a), which was not traversable with a GIF-H180 gastroscope (Olympus, Tokyo, Japan).

The patient did not have sustained symptom improvement after endoscopic balloon dilation, and it was decided to treat the refractory anastomotic stricture with endoscopic needle-knife therapy, carried out by an experienced endoscopist (BS).

A disposable single-use Doppler ultrasound probe (VTI Vascular Technology, Nashua, New Hampshire, USA) was introduced through the working channel of a GIF-H180 gastroscope to map the stric-

\section{Video 1}

Use of a Doppler ultrasound probe to guide endoscopic needle-knife therapy.

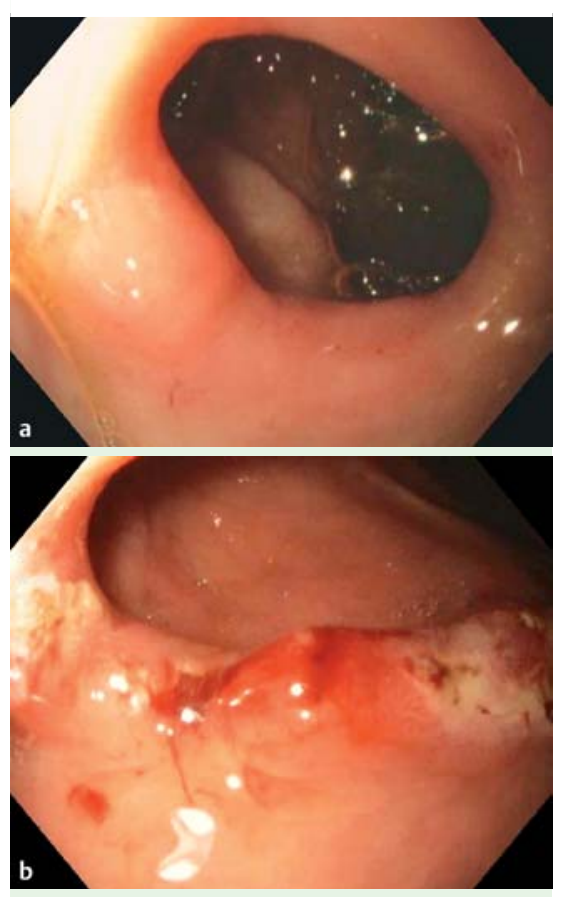

Fig. 2 Small recurrent anastomotic stricture 3 months after treatment: $\mathbf{a}$ before and $\mathbf{b}$ after further Doppler ultrasound-guided needleknife treatment.

ture areas with no large-volume blood flow ( Video 1).

Then electroincision was carried out with an Olympus triple-lumen needle-knife catheter (Olympus Medical Systems, Tokyo, Japan) ( Fig.1 b, Video 1). The procedure took 10 minutes and was uneventful, and 24 hours later the patient had significant symptom improvement. A follow-up sigmoidoscopy was accomplished without difficulty in intubating the anastomosis 3 months later. A small recurrent stricture at the IRA was further treated using the same method (๑ Fig. 2a,b).

Anastomotic strictures complicate colorectal surgery in $3-30 \%$ of all cases [1]. Endoscopic balloon dilation remains the preferred first-line treatment for benign anastomotic strictures due to its safety and feasibility [2], but long-term results appeared to be poor [3]. While there have been a few case reports of endoscopic trointestinal anastomotic strictures [4] needle-knife electroincision of upper gas- and anastomotic leaks/sinuses [5], use of the technique has not been reported for stricture treatment in the lower gastrointestinal tract. In addition, electroincision as reported was carried out in a "blind" fashion and not with Doppler ultrasound guidance. To our knowledge, this is the first case report of the use of Doppler ultrasound in endoscopic needle-knife treatment of anastomotic strictures. The procedure appears to be simple, safe, and feasible for treating benign anastomotic strictures.

Endoscopy_UCTN_Code_TTT_1AQ_2AF

Competing interests: None

\section{Y. $\mathbf{L i}^{1,2}$, B. Shen ${ }^{2}$}

Department of Gastroenterology, Peking Union Medical College Hospital, Beijing, China

2 Department of Gastroenterology/ Hepatology, Cleveland Clinic Foundation, Cleveland, Ohio, USA

\section{References}

1 Luchtefeld MA, Milsom JW, Senagore A et al. Colorectal anastomotic stenosis. Results of a survey of the ASCRS membership. Dis Colon Rectum 1989; 32: $733-736$

2 Garcea G, Sutton CD, Lloyd TD et al. Management of benign rectal strictures: a review of present therapeutic procedures. Dis Colon Rectum 2003; 46: 1451 - 1460

3 Nguyen-Tang T, Huber O, Gervaz $P$ et al. Long-term quality of life after endoscopic dilation of strictured colorectal or colocolonic anastomoses. Surg Endosc 2008; 22: $1660-1666$

4 Hordijk ML, Siersema PD, Tilanus HW et al. Electrocautery therapy for refractory anastomotic strictures of the esophagus. Gastrointest Endosc 2006; 63: 157-163

5 Lian L, Geisler D, Shen B. Endoscopic needle knife treatment of chronic presacral sinus at the anastomosis at an ileal pouch-anal anastomosis. Endoscopy 2010; 42 (Suppl 2): 14

Bibliography

DOI $10.1055 / \mathrm{s}-0030-1256840$

Endoscopy 2011; 43: E343

(c) Georg Thieme Verlag KG Stuttgart · New York . ISSN 0013-726X

\section{Corresponding author}

\section{B. Shen}

Digestive Disease Institute, Desk A31

Cleveland Clinic

9500 Euclid Ave

Cleveland

$\mathrm{OH} 44195$

USA

Fax: +216-444-6305

shenb@ccf.org 